\title{
INTERPRETANDO O LÍQUOR - COMO DADOS EPIDEMIOLÓGICOS PODEM AJUDAR NO RACIOCÍNIO CLÍNICO
}

\author{
ANALYZING CEREBROSPINAL FLUID - HOW EPIDEMIOLOGIC DATA CAN \\ HELP IN CLINICAL DECISION
}

Machado de Almeida BM, Targa CR, Batista CG, Farias FC, Oliveira JM, Gonçalves LA, Fernandes

MK, Souza RH, de Medeiros AR

\section{RESUMO}

Introdução: A meningite bacteriana sofreu grandes mudanças epidemiológicas após a introdução dos antibióticos e vacinas, passando de uma condição letal para tratável e prevenível. Compreender essas mudanças no perfil epidemiológico em nível local permitem planejar estratégias de terapia empírica. As alterações de líquor possuem papel fundamental nessa avaliação. Metodologia: Foi realizado um estudo transversal dos casos notificados de meningite entre janeiro de 2010 e junho de 2015 no Complexo Hospital de Clínicas - Universidade Federal do Paraná. Foram analisados a celularidade e citologia do líquor e os agentes etiológicos. Para as etiologias bacterianas, foi avaliado dados epidemiológicos. Resultados: Foram notificados 504 casos de meningite no período avaliado. A meningite asséptica foi a classificação epidemiológica mais comum. As meningites bacterianas com confirmação etiológica causadas por Neisseria meningitidis, Streptococcus pneumoniae ou Haemophilus influenzae ocorreram em $8,7 \%$ dos casos notificados, sendo que $30 \%$ delas ocorreram em menores de 1 ano. A N. meningitidis correspondeu a $61 \%$ desses casos, enquanto que S. pneumoniae a $34 \%$. As meningites neutrofílicas com mais de $75 \%$ de neutrófilos são causadas por tais bactérias em mais da metade (53\%). A meningite asséptica é a segunda principal etiologia (20\%) seguida de perto pela meningite tuberculosa (17\%). Os casos de meningite meningocócica se concentram em crianças até 1 ano (56\% dos casos), a meningite pneumocócica se concentra nos adultos entre 18 e 50 anos (46\%) e idosos (27\%). Conclusões: 0 conhecimento da epidemiologia local através da interpretação do líquor, somada à avaliação da faixa etária são importantes aliados da avaliação clínica para determinação do agente etiológico mais provável e podem ajudar na decisão terapêutica.

Descritores: Meningite. Líquor. Epidemiologia.

\section{ABSTRACT}

Introduction: Bacterial meningitis underwent major epidemiological changes after the introduction of antibiotics and vaccines from a lethal condition to treatable and preventable. Understanding these changes in local epidemiological profile can support empiric therapy strategies. Cerebrospinal fluid (CSF) changes play a fundamental role in this assessment. Methods: We conducted a cross-sectional study of reported cases of meningitis between January 2010 and June 2015 at the Clinical Hospital Complex of Federal University of Paraná. We analyzed the cellularity and cytology of CSF and the etiological agents. For bacterial etiologies it was evaluated epidemiological data. Results: There were 504 reported cases of meningitis during the study period. Aseptic meningitis was the most common epidemiological classification. Bacterial meningitis aetiological confirmation caused by Neisseria meningitidis, Streptococcus pneumoniae or Haemophilus influenzae occurred in $8.7 \%$ of reported cases and $30 \%$ of them occurred in less than 1 year. N. meningitidis corresponded to $61 \%$ of cases, while S. pneumoniae corresponded to $34 \%$. The neutrophilic meningitis over $75 \%$ of neutrophils on CSF were caused by such bacteria in over half (53\%). Aseptic meningitis were the second main cause (20\%) closely followed by tuberculous meningitis (17\%). Cases of meningococcal meningitis were concentrated in children up to 1 year (56\% of cases) and pneumococcal meningitis were concentrated in adults between 18 and 50 years (46\%) and older (27\%). Conclusions: The knowledge of local epidemiology through the interpretation of spinal fluid plus the evaluation of age are important allies of clinical evaluation to determine the most likely etiologic agent and can help in therapeutic decision.

Keywords: Meningitis. Cerebralspinal fluid. Epidemiology. 


\section{INTRODUÇÃO}

A meningite bacteriana, descrita no início do século XIX, já foi uma condição que evolui invariavelmente para o óbito se não tratada (Kaplan, 2015). É ainda hoje uma importante causa global de morbimortalidade, mas com importantes mudanças no perfil epidemiológico após introdução dos antibióticos a partir da década de 30 (Schwentker et al, 1984) e das vacinas a partir da década de 90 (Mclntyre et al, 2012). Porém, ainda possui alta letalidade especialmente na população susceptível abaixo de 2 meses (Thigpen et al, 2016).

As principais causas bacterianas de meningite são o $H$. influenzae, S. pneumoniae e $N$. meningitidis. Porém, há uma grande variedade de agentes etiológicos como os vírus, fungos, espiroquetas, ricketsioses, protozoários, além de medicamentos e outras causas não infecciosas como neoplasias e doenças autoimunes. Os vírus são a causa mais comum de meningite e, entre eles, os enterovírus correspodem a 85 a $95 \%$ dos casos (Mandell and Bennett, 2011).

\section{Tabela 1.}

\begin{tabular}{lc}
\hline Diagnóstico Diferencial das & Meningites \\
\hline Infecciosas & Mucobacterium \\
\hline Vírus & Espiroquetas \\
\hline Enterovírus (não poliovírus) & Treponema palidum \\
\hline Adenovírus & Borrelia burgdorferi \\
\hline Herpes vírus & Leptospira sp \\
\hline HIV & Protozoários \\
\hline Arbovírus & Taenia solium \\
\hline Parainfluenza & Naegleria fowleri \\
\hline Influenza & Causas não infecciosas \\
\hline Sarampo & Cistos e tumores \\
\hline Ricketsioses & intracerebrais \\
\hline Bactérias & Medicamentos \\
\hline Haemophilus influenzae & Antibióticos \\
\hline Neisseria meningitidis & Anti-inflamatórios não \\
\hline Streptococcus pneumoniae & esteoidais \\
\hline Listeria monocytogenes & Carbamazepina \\
\hline Streptococcus agalactiae & Ranitidina \\
\hline Diagnóstico Diferencial das & Deenças inflmatórias \\
\hline Lupus eritematoso & Outras \\
sistêmico & Crise convulsiva \\
\hline Pós procedimento & Migrania \\
\hline Neurocirurgia & Síndrome de Mollaret \\
\hline Anestesia peridural & \\
\hline Aplicações intratecais & \\
\hline
\end{tabular}

Adaptado de Mandell et al, 2011

Tendo em visto a mudança no perfil epidemiológico com introdução das vacinas, a variedade de causas e características epidemiológicas regionais e individuais, tornou-se um desafio o diagnóstico etiológico desta condição quando ainda não há a confirmação do agente etiológico. Portando, cada vez mais se faz necessário o conhecimento da epidemiologia local, bem como características do indivíduo como idade e comorbidades.

Quando se trabalha em um Núcleo de Epidemiologia dentro de um grande hospital, como o Complexo Hospital de Clínicas ( $\mathrm{CHC}$ ), é prática quase diária lidar com as meningites. Dentre os agravos de notificação compulsória, as meningites possuem grande importância, devido à alta letalidade, incluindo em crianças menores de 1 ano, ao temor de surto e à possibilidade de profilaxia oportuna na meningite meningocócica e por Haemophilus influenzae.

Do ponto de vista epidemiológico, há uma classificação etiológica baseada na identificação do agente etiológico, outros exames laboratoriais ou critérios clínicoepidemiológicos.

Quadro 1.

\begin{tabular}{|c|c|c|}
\hline $\begin{array}{l}\text { Classificação } \\
\text { da meningite }\end{array}$ & Definição & Exemplos \\
\hline Asséptica & $\begin{array}{l}\text { Causa viral ou } \\
\text { provavelmente viral }\end{array}$ & $\begin{array}{l}\text { Enterovírus; } \\
\text { Herpes vírus; } \\
\text { Sarampo }\end{array}$ \\
\hline $\begin{array}{l}\text { Outra } \\
\text { etiologia }\end{array}$ & Outra etiologia definida & $\begin{array}{l}\text { Criptococo; } \\
\text { Cisticercose }\end{array}$ \\
\hline $\begin{array}{l}\text { Não } \\
\text { especificada }\end{array}$ & Sem definição etiológica & \\
\hline $\begin{array}{l}\text { Outras } \\
\text { bactérias }\end{array}$ & $\begin{array}{l}\text { Outras bactérias que } \\
\text { não Haemophilus sp, } \\
\text { pneumococo e } \\
\text { meningococo. } \\
\text { Geralmente associadas } \\
\text { a infecções hospitalares }\end{array}$ & $\begin{array}{l}\text { S. aureus; } \\
\text { Estafilococo não } \\
\text { produtor de } \\
\text { coagulase; } \\
\text { Streptococcus sp }\end{array}$ \\
\hline
\end{tabular}

\section{Líquor alterado}

0 que fazer quando se detecta um líquor alterado? Em muitas ocasiões, os exames diretos são negativos e não se tem um diagnóstico etiológico no início do quadro. Aí vem a importância do conhecimento epidemiológico local. Não basta ter dados, se esses não forem avaliados, estudados, esmiuçados e discutidos para melhorar o conhecimento local e de toda a comunidade hospitalar. “Meningite neutrofílica! É bacteriana!" É mesmo? Qual a probabilidade de ser? Qual a probabilidade de não ser? 0 mesmo vale para meningites linfocíticas e as bordelines. Esses dados são de suma importância para complementar o raciocínio clínico.

\section{METODOLOGIA}

Foi realizado um estudo transversal dos casos notificados de meningite entre janeiro de 2010 e junho de 2015 no Complexo Hospital de Clínicas - Universidade 
Federal do Paraná. A base de dados foi o Sistema Nacional de Agravos de Notificação. Foram analisados a celularidade e citologia do líquor, bem como os agentes etiológicos, estratificados para cada faixa de neutrófilos. Para as etiologias bacterianas, foi avaliado a faixa etária e os sinais e sintomas marcados na ficha epidemiológica.

\section{RESULTADOS}

Foram notificados 504 casos de meningite no período avaliado. Isso corresponde a praticamente 8 casos por mês ou 2 casos por semana.

Gráfico 1. Número de notificações entre 2010 e 2015*

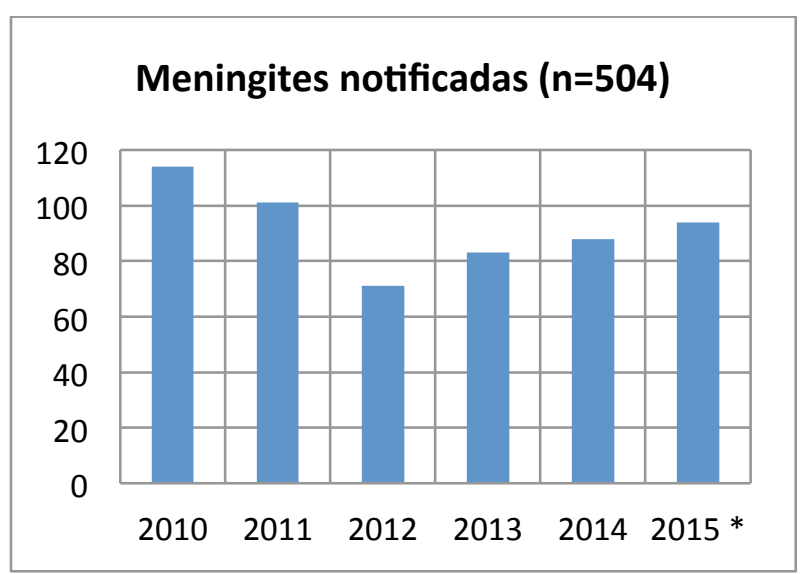

* estimativa baseada na média de casos até a metade do ano

\section{Agentes etiológicos}

o gráfico 2 apresenta a classificação etiológica dos casos, que varia desde uma meningite inflamatória pós-procedimento neurocirúrgico até uma meningite meningocócica.

Portanto, a principal classificação epidemiológica das meningites no $\mathrm{CHC}$ desde 2010 foram as meningites assépticas, que somaram 212 casos. Dentre os vírus isolados $(n=51)$, os enterovírus são a maioria, seguido pelo Herpes simples e varicela zoster. As meningites por outras bactérias incluem os casos de meningite associadas a derivações ou pós procedimento cirúrgico. 0 principal agente etiológico é o S. aureus, porém outros germes hospitalares possuem representatividade importante. Em relação às meningites de outra etiologia, o principal representante é o Cryptococcus neoformans, agente importante no paciente imunossuprimido, principalmente com a Síndrome da Imunodeficiência Adquirida (SIDA). A SIDA também é fator de risco importante para a meningite tuberculosa, porém em $40 \%$ desse tipo de meningite não há imunossupressão. As meningites bacterianas, representadas pelo Haemophilus influenzae, Neisseria meningitidis (meningococo) e Streptococcus pneumoniae (pneumococo) são a causa de $8,7 \%$ das meningites no
$\mathrm{CHC}$ e quase metade dos casos ocorrem em crianças até 5 anos.

Gráfico 2. Classificação etiológica das meningites

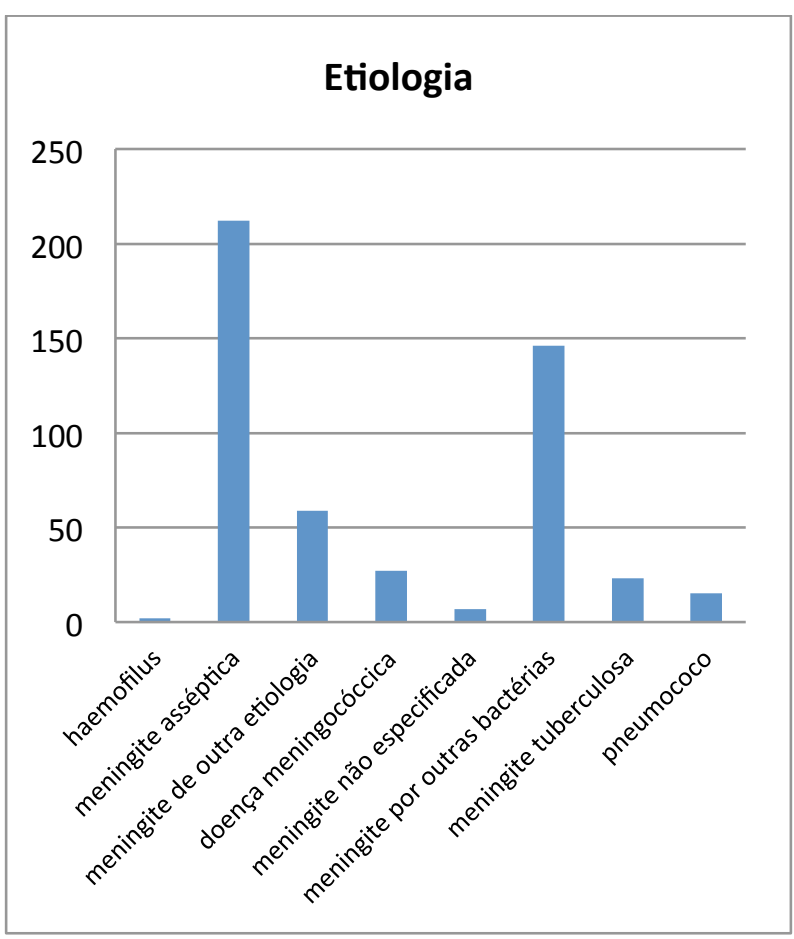

\section{Diferencial de celularidade no líquor}

A maioria das meningites possui predomínio de linfócitos (68\%), enquanto quase $1 / 3$ são neutrofílicos (gráfico 3).

\section{Gráfico 3.}

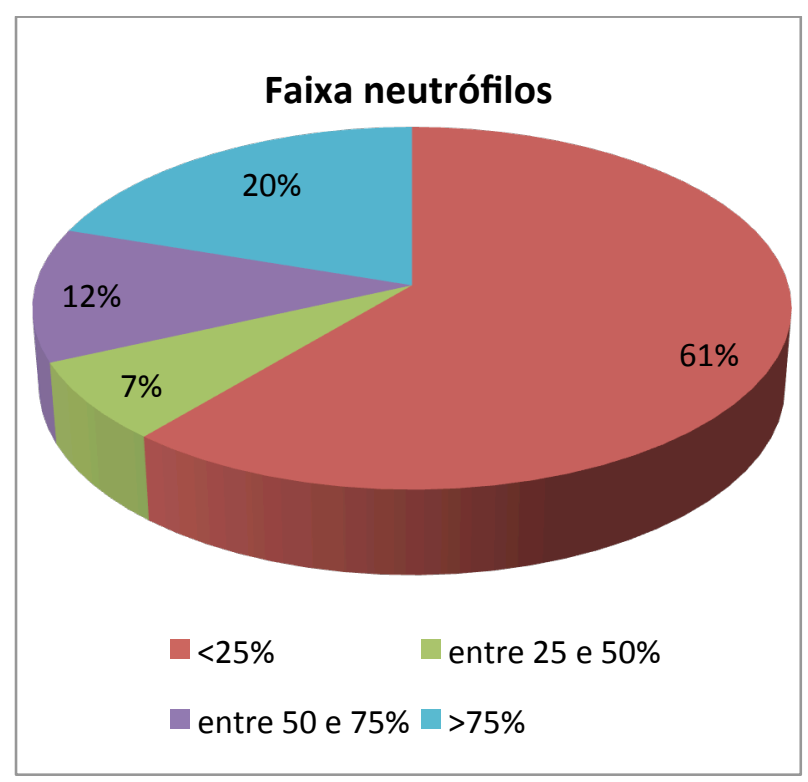

Dentre tantas possíveis causas é difícil avaliar a etiologia baseado na citologia do líquor. Uma análise estratificada ajuda nessa interpretação.

No gráfico 4, fica evidente a curva descendente das meningites por outras bactérias e ascendente das 


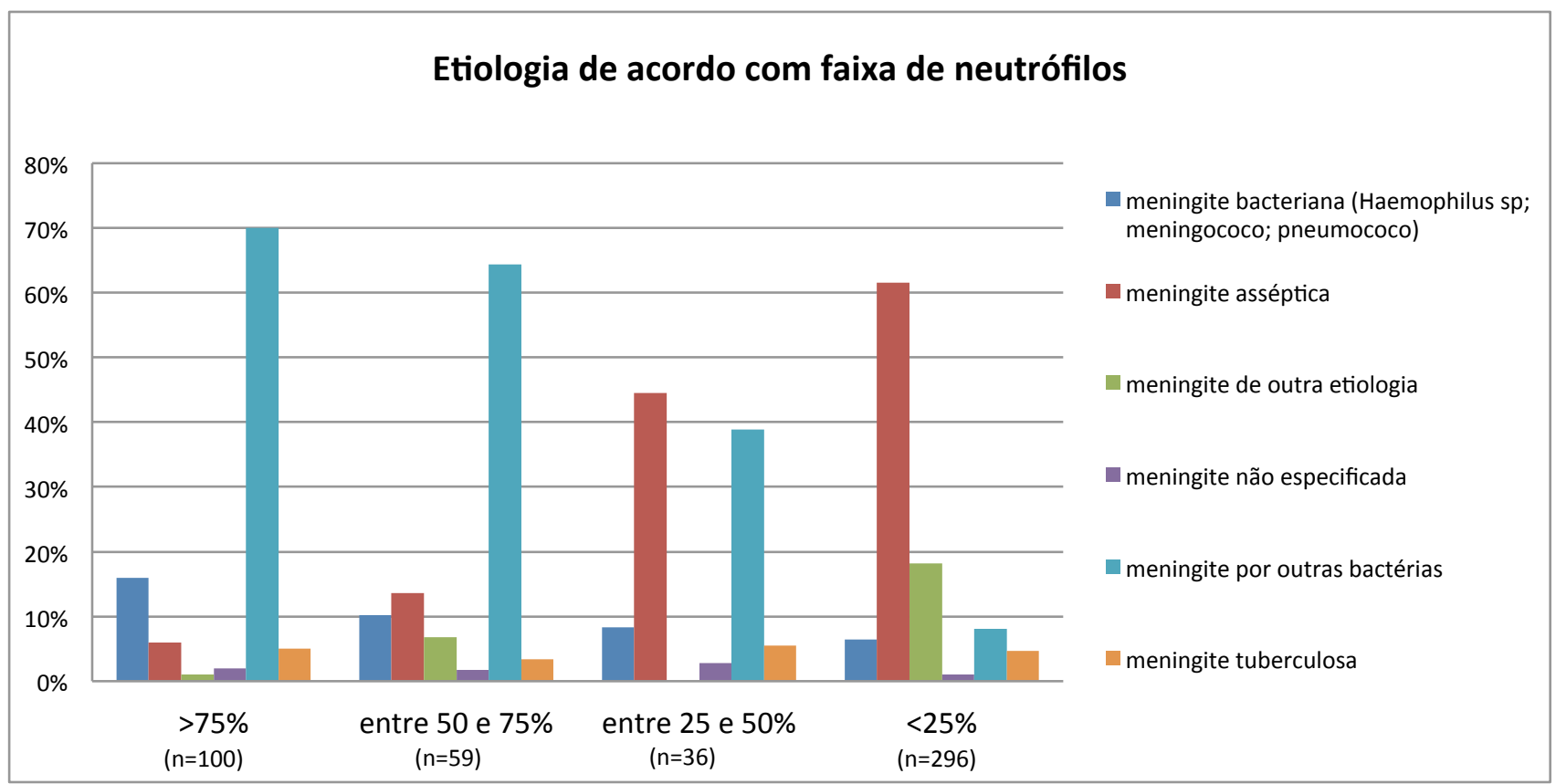

Gráfico 5.

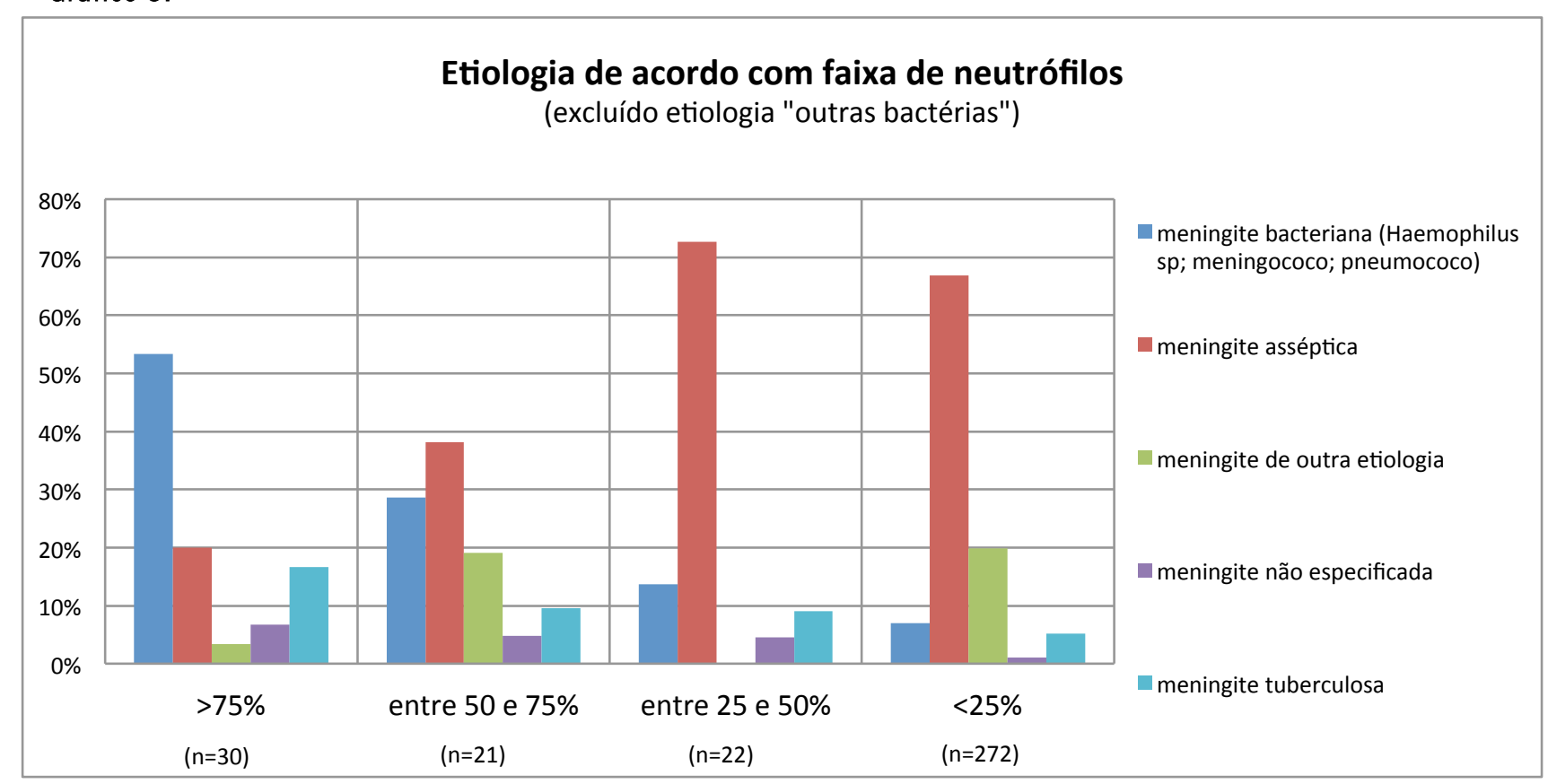

meningites assépticas na medida em que se reduz a quantidade de neutrófilos. Porém, quase que a totalidade das meningites por outras bactérias são infecções hospitalares, relacionadas à derivação ou a procedimentos neurocirúrgicos, fatores esses facilmente identificáveis. Quando se exclui essa condição (gráfico 5) é possível verificar a predominância das meningites bacterianas (>50\%) nas amostras com contagem de neutrófilos acima de $75 \%$ e também com uma queda progressiva de sua representatividade nas outras faixas mais baixas de neutrófilos.

Atenção deve ser dada à meningite por tuberculose, que apesar de predominar na faixa linfocítica, é neutrofílico em $30 \%$ dos casos (gráfico 6).

\section{Meningites bacterianas}

Em relação às meningites bacterianas (gráfico 7), a maioria dos casos se concentra em menores de 1 ano. Quando se estratifica a etiologia, é possível verificar a diferença entre menigococo, que afeta crianças até 5 anos em $56 \%$ dos casos, do pneumococo, que predomina em adultos e idosos (73\% dos casos). Dos 27 casos de doença meningicócica, apenas $22 \%$ foram sorotipados e desses a maioria é do sorogrupo $B$.

Os principais sintomas nas meningites bacterianas são febre, vômito, cefaléia e petéquias. A 


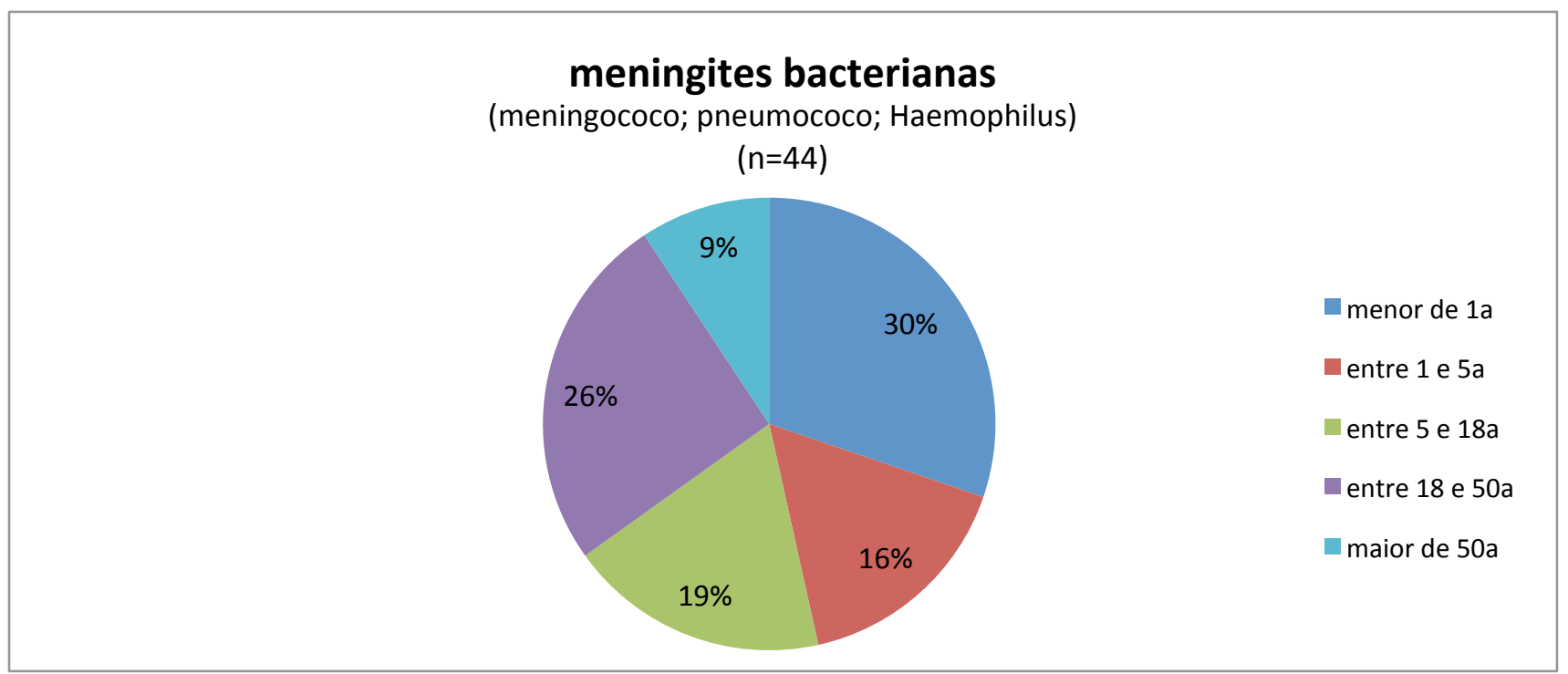

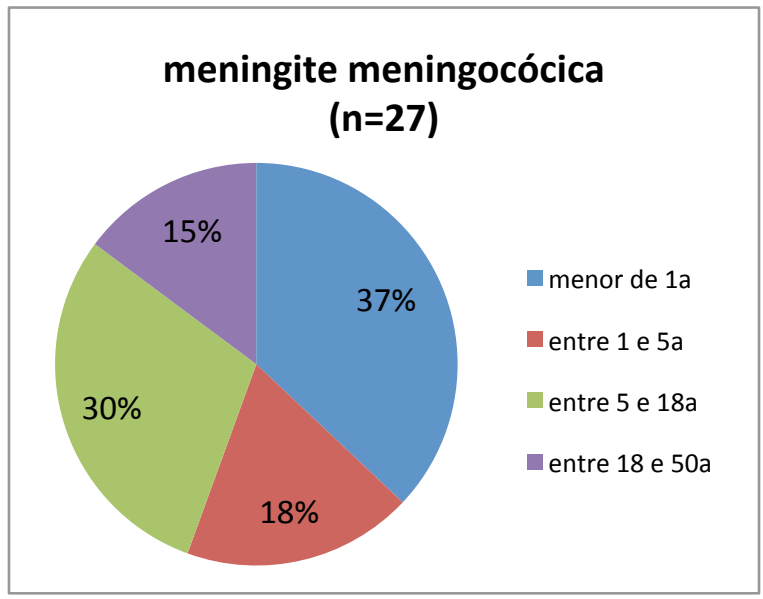

presença de petéquias, ou sufusões hemorrágicas é altamente específica de doença meningocócica, estando indicada profilaxia nessa situação mesmo numa meningite sem confirmação etiológica de meningococo de acordo com o Guia de Vigilância em Saúde do Ministério da Saúde (Brasil - MS, 2014).

\section{Considerações}

O Complexo Hospital de Clínicas é referência em pediatria, procedimentos neurocirúrgicos, hematologia, infectologia e possui unidade de terapia intensiva. Isso faz com que o espectro das meningites seja bastante amplo. Porém, frente a um líquor alterado, com o conhecimento de alguns dados clínicos, diferencial da citologia e faixa etária, é possível prever a etiologia com certa precisão. Com esse estudo, passamos a entender melhor a realidade local de um hospital terciário, com suas semelhanças e diferenças em relação às outras instituições. O conhecimento epidemiológico local dá subsídio para o raciocínio clínico e permite a tomada de decisões com maior precisão e segurança.

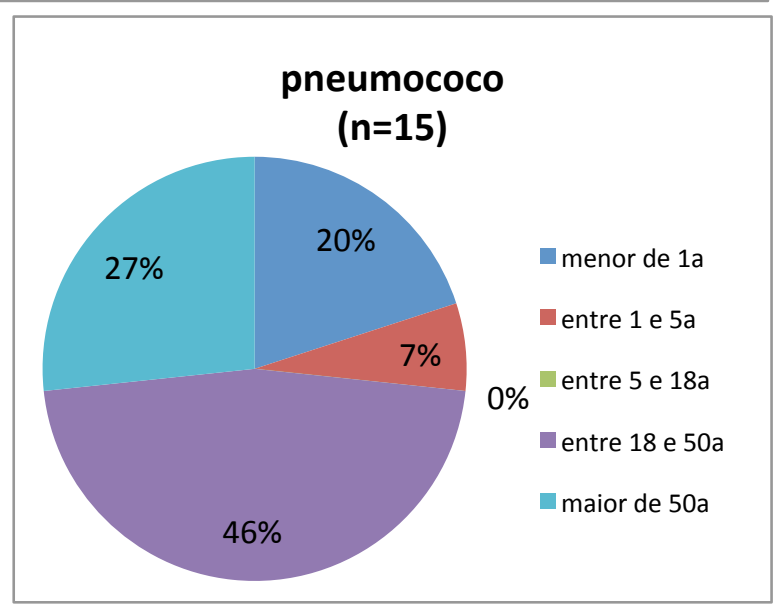

\section{REFERÊNCIAS}

1. Kaplan SL, Bacterial meningitis in children older than one month: Treatment and prognosis, UpToDate, 2015 Jun, disponível em < http://www.uptodate.com/contents/bacterialmeningitis-in-children-older-than-one-month-treatmentand-

prognosis?source=search_result\&search=meningite \& selectedTitle=3 150>. Acesso em: 01/03/2016.

2. Thigpen MC, Whitney CG, Messonnier NE, Zell ER, Lynfield R, Hadler JL, Harrison LH, Farley MM, Reingold A, Bennett NM, Craig AS, Schaffner W, Thomas A, Lewis MM, Scallan E, Schuchat A, Emerging Infections Programs Network; Bacterial meningitis in the United States, 1998-2007; N Engl J Med. 2011;364(21):2016.

3. McIntyre PB, O'Brien KL, Greenwood B, van de Beek D; Effect of vaccines on bacterial meningitis worldwide.; Lancet. 2012 Nov;380(9854):1703-11. 
Gráfico 7.

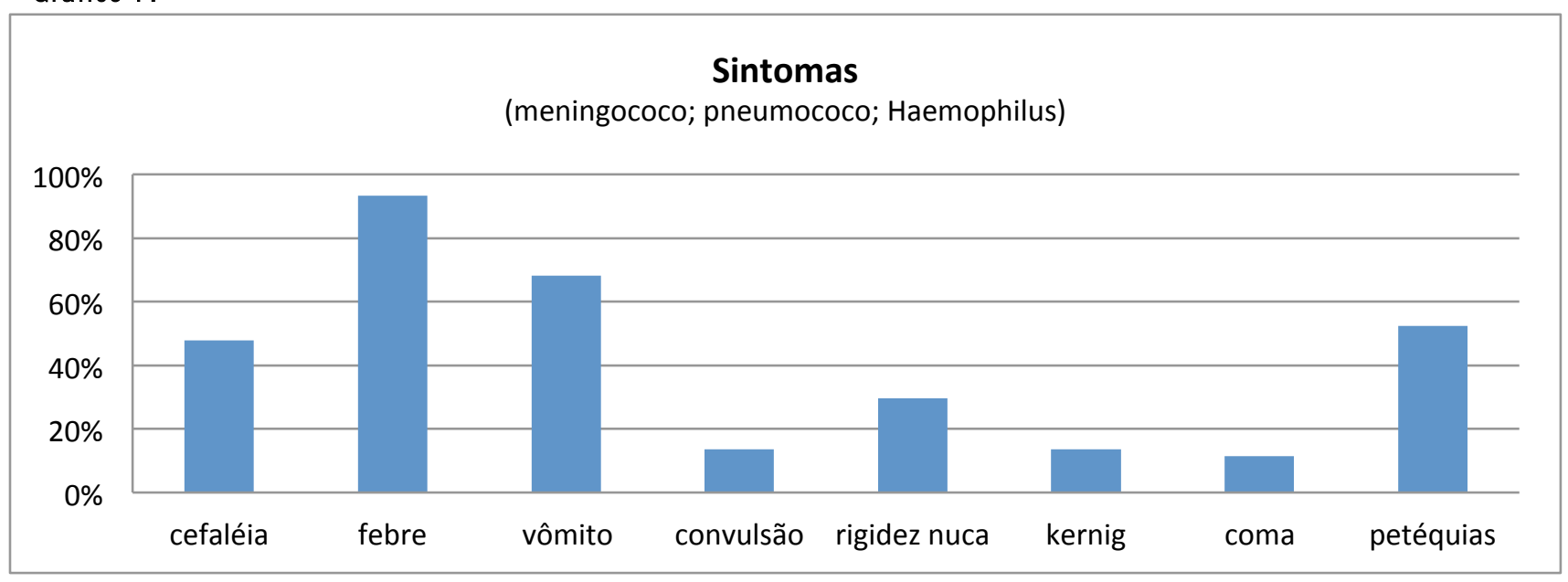

4. Scheld WM, Koedel U, Nathan B, Pfister HW; Pathophysiology of bacterial meningitis: mechanism(s) of neuronal injury; J Infect Dis. 2002;186 Suppl 2:S225.

5. Schwentker FF, Gelman S, Long PH; Landmark article April 24, 1937. The treatment of meningococcic meningitis with sulfanilamide. Preliminary report. By Francis F. Schwentker, Sidney Gelman, and Perrin H. Long; JAMA. 1984;251(6):788.

6. Mandell, Douglas, and Bennett's; Principles and Practice of Infectious Diseases; seventh edition, 2011

7. Brasil, Ministério da Saúde, Secretaria de Vigilância em Saúde; Guia de Vigilância em Saúde; 1a edição, 2014; versão eletrônica

8. Brasil, Ministério da Saúde; DataSus/TabNet disponivel em: http://dtr2004.saude.gov.br/sinanweb/tabnet/tabnet ?sinannet/meningite/bases/meninbrnet.def acessado em 25-07-2015

9. Azevedo LCP, Toscano CM, Bierrenbach AL; Bacterial Meningitis in Brazil: Baseline Epidemiologic Assessment of the Decade Prior to the Introduction of Pneumococcal and Meningococcal Vaccines; PLoS ONE. 2013;8(6): e64524 